\title{
Uma genealogia intelectual da paz
}

Rubens Leonardo Panegassi ${ }^{1}$

Resenha recebida em: 25/04/2016

Resenha aprovada para publicação em: 23/10/2016

REZA, Germán A. de la. A invenção da paz: da República Cristã do duque de Sully à Federação das Nações de Simón Bolivar. Trad. Jorge Adelqui Cáceres Fernández e André Figueiredo Rodrigues. São Paulo: Humanitas, 2015.

A invenção da paz: da República Cristã do duque de Sully à Federação das Nações de Simón Bolívar é um estudo historiográfico cujo escopo é a investigação da tradição intelectual abarcada pelos diferentes projetos concebidos para a criação de confederações interestatais. De modo sumário, pode-se definir o livro como um estudo de História das Ideias, cujo enfoque se atém à recuperação do fio condutor existente entre os diversos pensadores que deram atenção à questão da criação de ligas confederadas na história do ocidente e sua penetração e difusão no âmbito da América Latina. O autor do livro, o pesquisador mexicano Germán A. de la Reza, é doutor em Filosofia e História pela Universidade Toulouse Le Mirail e figura como referência quando o assunto em pauta são ideias confederativas no contexto latino-americano, o que é notável pelo título de seus principais trabalhos, dentre os quais é possível destacar Les nouveaux défis de l'intégration en Amérique Latine, El Congreso de Panamá y otros ensayos de integración latinoamericana en el siglo XIX e El ciclo confederativo: historia de la integración latinoamericana en el siglo XIX.

Publicado originalmente pela editora Siglo XXI, A invenção da paz é o primeiro livro de Reza editado no Brasil e tem a virtude de apresentar ao público um eficiente panorama do processo de transmissão e recepção do pensamento confederativo nos mais diversos contextos históricos, desde Filipe II da Macedônia até Simón Bolívar, passando

\footnotetext{
${ }^{1}$ Doutor em História pela Universidade de São Paulo. Professor de História Moderna e Contemporânea da Universidade Federal de Viçosa. Pesquisa: A vocação imperial e o reino imaginário: a linguagem política portuguesa nos governos de D. Manuel e D. João III (1495-1557), CNPq. Endereço: Av. Olívia de Castro Almeida, no 295, ap. 203. Bairro Clélia Bernardes, Viçosa, MG. CEP 36570-000. e-mail: rubenspanegassi@gmail.com.br
}

\section{GANPHLAC}

Revista Eletrônica da ANPHLAC, ISSN 1679-1061, №. 22, p. 377-382, Jan./Jun., 2017.

http://revista.anphlac.org.br 
por diferentes nomes ligados ao pensamento anfictiônico, tanto aqueles de maior circulação, como Jean-Jacques Rousseau e Emmanuel Kant, como outros mais desconhecidos, como Émeric Crucé e Cecílio del Valle.

Dividido em onze capítulos, afora introdução e conclusão, o livro organiza-se em dois eixos bem definidos. O primeiro deles é o da reconstituição do ideário que norteia os primeiros projetos de integração europeia, tal como o da República cristã sugerida pelo duque de Sully, até o esgotamento deste ideário no plano europeu, com o conde de Saint-Simon e sua proposta de um governo geral para toda a Europa. O segundo eixo trata do deslocamento da tradição anfictiônica para a América Latina, lugar que levaria a efeito a ideia de pacificação confederada com Simón Bolívar e o Congresso do Panamá, em 1826.

Em função desta premissa, a recuperação da "genealogia intelectual" dos projetos de integração interestatal levada a cabo por Germán A. de la Reza nos conduz às anfictionias da Grécia antiga e sua mitologia, onde figura a primeira dessas ligas: organizada pelo filho de Prometeu, Anfictião, nela teriam sido definidas regras para o estabelecimento de vínculos de reciprocidade assentados em elementos de caráter etnocêntrico, tais como continuidade geográfica e identidade cultural compartilhada. Por sua vez, em termos concretos, foi Filipe II da Macedônia quem organizou, no ano de 388 a. C., a Liga helênica, a mais famosa e sofisticada das anfictionias da Antiguidade, com sede no Istmo de Corinto.

Em seu viés teórico, os pressupostos anfictiônicos figuram na pena de autores como Políbio, Tucídides, Heródoto, Ésquines, Aristófanes, Estrabão e Demóstenes, de modo que, em boa medida, seu impacto no pensamento jurídico e político do ocidente definiu os contornos das normas jurídicas romanas, ecoando nos escritos de autores como Cícero, Tácito e Plutarco. Além disso, a perpetuação deste ideário pode ser notada nas formulações de autores como Pierre Dubois, Dante Alighieri e Marsílio de Pádua, autores que, nos séculos XIII e XIV, debateram-se com a questão do pacifismo no contexto belicista que se seguiu à queda do Império Romano.

Para o autor, a belicosidade do período medieval se acentuou com a Reforma e o desmoronamento da unidade cristã ocidental no início da Época Moderna. A

\section{GANPHLAC}


persistência destes conflitos e seus desdobramentos em situações dramáticas, como foi o Massacre de São Bartolomeu em 1579, definiu um ambiente intelectualmente estéril no âmbito das ideias confederativas, mesmo a despeito dos valores humanistas propagados por um autor como Erasmo de Roterdã. Seria apenas no século XVII, com a edição das Memórias das sábias e reais economias do estado, domésticas, políticas e militares de Henrique o Grande, de autoria do francês Maximilien Béthune, duque de Sully, que a tradição anfictiônica ganharia novo fôlego no ocidente.

Definida como um gênero híbrido em que se articulam crônica palaciana e documentos oficiais, as Memórias de Sully desenham um projeto de união europeia calcado na tolerância religiosa e alicerçado na constituição de uma República cristã formada por todos os estados, reinos, repúblicas e senhorios europeus que tivessem o cristianismo como profissão de fé. Entretanto, foi Émeric Crucé - também francês e contemporâneo de Sully - quem efetivamente proporia as bases do primeiro projeto de confederativo europeu.

Do projeto de Crucé, Reza sugere que seu enfoque é multilateral, pacifista e global, mas que, todavia, assenta-se em razões comerciais. Ainda assim, destaca o interesse do francês em aproximar todas as culturas e religiões existentes no seu tempo. De fato, Crucé sugere uma assembleia confederada que pressupõe o envolvimento de embaixadores permanentes oriundos não apenas das monarquias europeias, mas também de lugares tão diversos quanto Turquia, Rússia, China ou Etiópia.

Definitivamente, o século XVII é apontado por Reza como o momento em que os projetos de caráter anfictiônico ganharam maior fôlego. Vários são os autores apresentados em seu livro que se detiveram sobre o assunto, dentre os quais o holandês Hugo Grocio, com $O$ direito da guerra e da paz; o alemão Ernesto de Hesse-Rheinfels, com $O$ católico sincero e discreto ou o discurso dos sentimentos, ideias, reflexões razoáveis, livres e moderadas sobre o estado atual da religião do mundo, por uma pessoa que está firmemente unida ao catolicismo romano; outro francês, de nome Pierre Nicole, com o tratado Dos meios para conservar a paz entre os homens; e ainda, o inglês William Penn, que publicou Um ensaio sobre a paz presente e futura da Europa. Em suma, para Germán de la Reza, a produção anfictiônica deste período prepararia

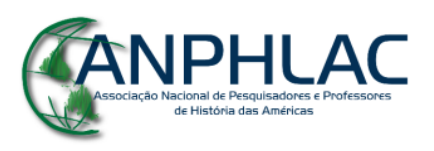

Revista Eletrônica da ANPHLAC, ISSN 1679-1061, №. 22, p. 377-382, Jan./Jun., 2017.

http://revista.anphlac.org.br 
terreno para uma obra de síntese, tal como foi o Projeto para fazer a paz perpétua na Europa, escrita pelo francês Charles Irénée Castel, o abade de Saint Pierre.

A contribuição do abade de Saint Pierre à tradição anfictiônica define-se por sua capacidade em atualizá-la e reinterpretá-la. Com efeito, seus pressupostos são compartilhados por virtualmente todos os autores da anfictionia, o que denota sua capacidade de vocalização deste ideário, donde terá atraído a atenção de nomes como o de Jean-Jacques Rousseau, que elaborou uma síntese do Projeto: publicado em 1761, Reza nos assegura que o Extrato do Projeto de paz perpétua do senhor abade de Saint Pierre foi responsável por transformar o livro do abade em uma das mais importantes referências da filosofia política de finais do século XVIII e inícios do XIX.

A despeito da importância que o Projeto de Saint Pierre ganhou, Germán de la Reza assinala que seu maior limite é a subordinação de suas teses ao sistema absolutista. Limite que seria superado em 1795 com o opúsculo Para a paz perpétua, onde o filósofo alemão Emmanuel Kant sugere que a legitimidade da confederação não reside exclusivamente nos tratados de segurança multilaterais, mas também na liberdade republicana dos povos. Com efeito, ainda que a recepção do ideário kantiano tenha sido associada à intelectualidade germânica do período, sua contribuição ao ideário anfictiônico reside em sua proposta para a criação de uma ordem cosmopolita pacífica que transcenda a Europa, e possa ser posta em prática a qualquer grupo de nações.

Por sua vez, a transição do século XVIII para o XIX é apontada por Reza como um momento de incisão na trajetória histórica do pensamento anfictiônico. Doravante, o problema da pacificação confederada se deslocaria para os Balcãs e para a América Latina, sendo no novo mundo que floresceria a mais relevante contribuição anfictiônica da modernidade. Ainda assim, há duas obras notáveis produzidas no contexto europeu. A primeira, publicada em 1806 por um autor anônimo, intitulada Pensamentos filosóficos e políticos sobre as desgraças que acarretam as guerras e sobre o meio para fazê-las cessar, e a segunda, publicada em 1814 e de autoria de Claude Henri de Rouvroy, o conde de Saint-Simon, intitulada Da reorganização da Sociedade Europeia, ou da necessidade e os meios para unir os povos da Europa num só corpo político,

\section{GANPHLAC}


conservando a independência nacional de cada um, cuja proposta se assenta na constituição de uma Europa confederada e regida por um governo único.

Mas foi na América Latina que o pensamento anfictiônico ganhou novos contornos, principalmente com Simón Bolívar e o Congresso do Panamá, em 1826. Notório resultado do impacto da veiculação da anfictionia, sobretudo a partir dos Extratos de Rousseau, o Congresso redundou numa série de tratados que, todavia, jamais foram aprovados pelos países partícipes, com exceção da Colômbia. Entretanto, não é o sucesso do empreendimento que interessa a Germán de la Reza, uma vez que a temática do ideário anfictiônico no novo mundo abre precedente para que o autor conecte a iniciativa bolivariana a outras do mesmo gênero.

A primeira delas é a do Ministro de Negócios Estrangeiros e Guerra do Reino Unido de Portugal, Brasil e Algarves, Silvestre Pinheiro Ferreira, que propôs um Tratado de confederação e garantia mútua de independência dos estados americanos que, embora não possa ser considerado um plano de caráter anfictiônico, aborda temas como liberdade de comércio, direitos de navegação e cidadania. Outro nome, este ligado de modo mais estreito à iniciativa confederativa, é o do hondurenho José Cecílio del Valle, que publica o Projeto de confederação americana. Sonhava o abade de São Pedro: e eu também sei sonhar. Por fim, destaca a iniciativa do mexicano Lucas Alamán e sua Assembleia americana permanente, o "Pacto de Família", que se configuraria como espaço de contínua negociação de acordos entre os países envolvidos.

A despeito das diferenças, todos os projetos mencionados por Reza compartilhavam o objetivo de resguardar a integridade e a autodeterminação dos jovens países da América Latina. Mas foi o projeto de Alamán que produziu maior efeito, ao resultar no congresso latino-americano realizado em Lima, em 1848, e cujo intento foi o de conter as hostilidades das potências colonialistas europeias, notadamente as da Espanha. Por sua vez, o relativo fracasso da iniciativa, em associação às ameaças externas, motivaria dois outros congressos, também em Lima: um em 1857 e outro em 1865. Todavia, o autor assinala que ambos os congressos perderam paulatinamente sua lógica anfictiônica ao se concentrarem na promoção da arbitragem internacional.

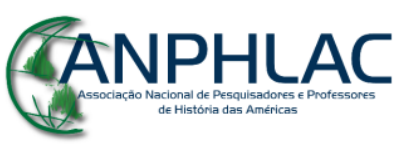

Revista Eletrônica da ANPHLAC, ISSN 1679-1061, №. 22, p. 377-382, Jan./Jun., 2017.

http://revista.anphlac.org.br 
Essa nova orientação redundaria na Primeira Conferência Interamericana de Washington, em 1889, cujos tratados também jamais seriam aprovados pelos parlamentos dos países representados, como ocorreu nas edições dos congressos anteriores do Panamá e de Lima. Mas, na perspectiva de Germán de la Reza, o que se deve reter é que tanto os projetistas pan-europeus quanto os congressos de inspiração bolivariana deram um passo de suma importância à criação dos programas comunitários mais importantes do século XX, tais como a Organização das Nações Unidas, em 1945, e o Tratado de Roma, de 1958, ou os acordos de integração latino-americana, de 1960.

Em resumo, ao passo que Reza recupera a articulação existente entre o ideário anfictiônico latino-americano, o europeu e o greco-romano, enfatiza seu potencial universalista. Possivelmente, o maior limite do livro de Reza seja de cunho teórico, visto que sua demonstração da trajetória do ideário anfictiônico é demasiadamente linear e causal. Mas o fato é que esta abordagem pode ampliar o leque de leitores para além do público universitário, uma vez que as ideias são apresentadas com clareza e fluidez.

\section{GANPHLAC}

